Check for updates

Cite this: Chem. Commun., 2020, 56, 13363

Received 3rd September 2020, Accepted 1st October 2020

DOI: $10.1039 / \mathrm{d} 0 \mathrm{cc} 05944 \mathrm{~g}$

rsc.li/chemcomm

\section{A concise route to MK-4482 (EIDD-2801) from cytidine $\dagger$}

\author{
N. Vasudevan, ${ }^{a}$ Grace P. Ahlqvist, (D) ${ }^{\text {b }}$ Catherine P. McGeough, ${ }^{b}$ \\ Dinesh J. Paymode, ${ }^{a}$ Flavio S. P. Cardoso, (D) ${ }^{a}$ Tobias Lucas, ${ }^{c}$ Jule-Phillip Dietz, ${ }^{c}$ \\ Till Opatz, (D) ${ }^{\mathrm{c}}$ Timothy F. Jamison, (D) ${ }^{\mathrm{b}}$ Frank B. Gupton ${ }^{\mathrm{a}}$ and David R. Snead (D) *a
}

A two-step route to MK-4482 (EIDD-2801, 1) was developed consisting of an esterification and hydroxamination of cytidine. The selective acylation and direct amination eliminate the need for protecting and activating groups and proceed in overall yield of $75 \%$, a significant advancement over the reported yield of $17 \%$. The step count is reduced from five transformations to two, and expensive uridine is replaced with the more available cytidine.

Remdesivir has presented itself as an option for COVID-19 treatment; however, improvements upon this initial solution are still desired. Fulfilling demand is complicated by issues related to raw material supply, ${ }^{1 a}$ price, ${ }^{1 b}$ and synthetic route length. ${ }^{2}$ MK-4482 (EIDD-2801) $^{3}$ presents an interesting complement to remdesivir for COVID-19 treatment. It is structurally simple in comparison, and it can likely be made from abundant raw materials. These factors would be expected to alleviate supply chain difficulties and reduce costs. Encouragingly, MK-4482 shows potential to treat mice with remdesivir resistant strains of COVID-19, and the active pharmaceutical ingredient (API) is orally bioavailable. These advantages prompted Merck to license the drug candidate from Ridgeback Biotherapeutics. ${ }^{4}$

The initial disclosure of MK-4482 is the only synthesis which appears in the open literature (Fig. 1), and not unexpectedly there are significant opportunities for improvement over this early route: ${ }^{5}$

- The API is constructed over five chemical transformations.

- The route suffers from low yield (17\% maximum, yield of diol deprotection not disclosed).

- The step count is lengthened by derivatizations and protections.

\footnotetext{
${ }^{a}$ Medicines for All Institute, 737 N. 5th St., Box 980100, Richmond, VA, 23298-0100, USA. E-mail: drsnead@vcu.edu

${ }^{b}$ Department of Chemistry, Massachusetts Institute of Technology, 77 Massachusetts Ave, Cambridge, Massachusetts, 02139, USA

${ }^{c}$ Department of Chemistry, Johannes Gutenberg University, Duesbergweg 10-14, Mainz 55128, Germany

$\dagger$ Electronic supplementary information (ESI) available. See DOI: 10.1039/ d0cc05944g
}

- Uridine, an expensive material of limited availability, is the synthetic starting point.

Building the API from cytidine instead of uridine presents several advantages. First, raw material costs can be decreased because cytidine is $\sim 40 \%$ of the price of uridine. ${ }^{6}$ Secondly, there is potential to reduce the synthesis to a two-step sequence comprising esterification and transamination (Fig. 2).

We began our exploration by examining direct transamination of cytidine with hydroxylamine. ${ }^{7}$ Older literature studies suggested that mono-hydroxamination can be achieved under the right concentration, temperature and $\mathrm{pH}$, while minimizing over-reaction of the substrate. ${ }^{7 a, b}$ More recently this finding was repeated by Purohit with preparative HPLC separation ${ }^{7 c}$ while Painter claimed difficulties with the procedure leading to $20 \%$ yield. ${ }^{7 d}$ In our hands, with slight adjustment of the reaction conditions, $N(4)$-hydroxycytidine (NHC, 3) was synthesized in $70 \%$ assay yield (AY). Importantly, upon concentration, pure NHC was obtained by simple crystallization directly from the reaction mixture in $50 \%$ isolated yield.

We also explored transamination of cytidine isobutyryl ester $\mathbf{4}$, and surprisingly, with the use of $\mathrm{NH}_{2} \mathrm{OH} \cdot \mathrm{H}_{2} \mathrm{SO}_{4}$ in $\mathrm{iPrOH}$,

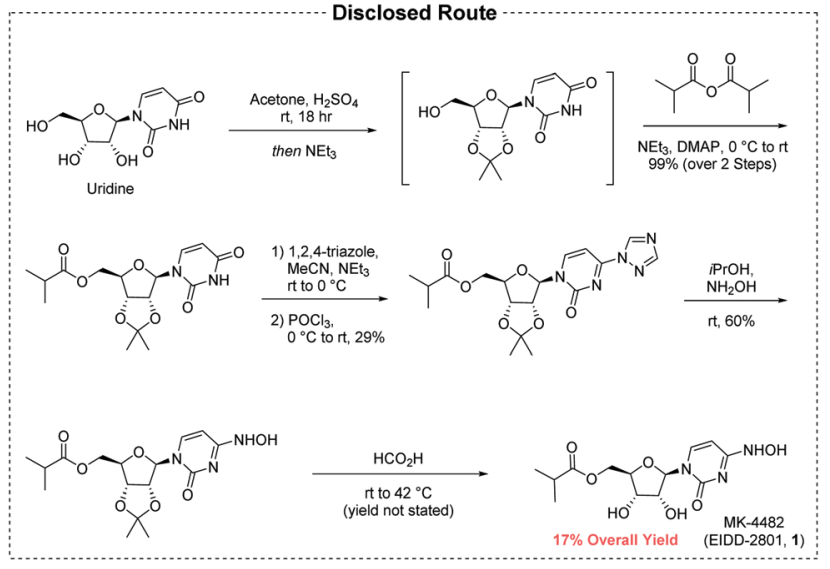

Fig. 1 The first generation route to MK-4482 from uridine. 


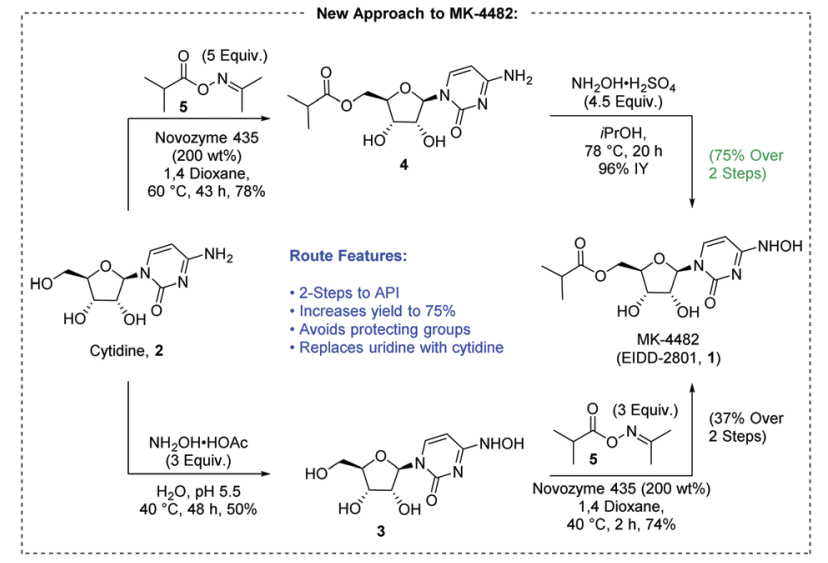

Fig. 2 A new route to $M K-4482$ from cytidine.

dihydroxamination was avoided completely. We were quite pleased to find that the ester remained intact. MK-4482 was obtained from 4 in 96\% isolated yield (IY), demonstrating viability of direct hydroxamination from either cytidine reaction pathway.

Selective acylation remained as the largest technical uncertainty toward production of a shorter, protecting group free route to MK-4482. The esterification of NHC 3 would need to be selective for one of four hydroxyl groups, and the literature suggests that the $N$-hydroxy group is most reactive toward acylation by chemical means. ${ }^{7 d, 8}$ Enzyme catalyzed esterification of cytidine has achieved this goal by making use of vinyl esters and anhydride acyl donors. ${ }^{9}$ The use of oxime ester transfer agents was of particular interest due to the structural similarity with $N$-hydroxycytidine, 3 , and excellent selectivity was observed with uridine though cytidine was unfortunately reported to give the $O, N$-diacylated product. ${ }^{10}$ We were curious whether this approach would work to form the desired $\alpha$-branched esters.

Surprisingly immobilized CALB (Candida Antarctica Lipase B) provided the desired selectivity not only for $N$-hydroxycytidine but also for cytidine. Isobutyric oxime ester $\mathbf{5}$ was used as the acyl transfer agent with solid supported enzyme (200 wt\%, $1.5 \mathrm{~mol} \%$ ). A sufficient excess of the oxime ester was necessary to drive the reaction to completion, and early results have been best with 1,4-dioxane. MK-4482 was isolated in $74 \%$ yield from 3 , and 4 was isolated in $78 \%$ yield from cytidine. A traditional chemically catalyzed acylation was developed to provide a nonenzymatic option to reach $4 .{ }^{11}$ Though inexpensive this option might not be preferable to the enzymatic route. More reagents are added to the reaction system and a greater number of byproducts are formed which might hamper efforts to purify the intermediate at scale. Conversion was stopped at $90 \%$ to halt over-acylation of the product, resulting in an isolated yield of $76 \%$ of 4 . Similarly, an alternative route to 3 was developed from uridine. $^{11}$

This completes two concise routes to MK-4482, which differ in the order of synthetic transformations. When conducting esterification first, MK-4482 is obtained in $75 \%$ yield, and it is made in $37 \%$ yield when hydroxyamination is conducted first. The step count is reduced from five transformations to two, and the more expensive uridine is replaced with cytidine. The use of protecting groups and derivatization is eliminated. We plan to further report on the optimization of this preliminary result to refine catalyst loadings, solvent selection, and yield while developing process-amenable isolation sequences.

We thank the Bill and Melinda Gates Foundation for their longstanding support of our research. Grace Ahlqvist would also like to acknowledge support by the National Science Foundation Graduate Research Fellowship under Grant No. 1745302.

\section{Conflicts of interest}

There are no conflicts to declare.

\section{Notes and references}

1 (a) An Update on COVID-19 from our Chairman \& CEO, Gilead Sciences, Inc., accessed July 1, 2020, https://stories.gilead.com// articles/an-update-on-covid-19-from-our-chairman-and-ceo; $(b)$ An Open Letter from Daniel O’Day, Chairman \& CEO, Gilead Sciences, Gilead Sciences, Inc, accessed July 1, 2020, https://www.gilead.com/news-andpress/press-room/press-releases/2020/6/an-open-letter-from-daniel-odaychairman-ceo-gilead-sciences.

2 (a) L. Zhang, S. Neville, E. Carra, W. Lew, B. Ross, Q. Wang, L. Wolfe, R. Jordan, V. Soloveva, J. Knox, J. Perry, M. Perron, K. M. Stray, O. Barauskas, J. Y. Feng, Y. Xu, G. Lee, A. L. Rheingold, A. S. Ray, R. Bannister, R. Strickley, S. Swaminathan, W. A. Lee, S. Bavari, T. Cihlar, M. K. Lo, T. K. Warren and R. L. Mackman, J. Med. Chem., 2017, 60, 1648; (b) C. De Savi, D. L. Hughes and L. Kvaerno, Org. Process Res. Dev., 2020, 24, 940; (c) T. Vieira, A. C. Stevens, A. Chtchemelinine, D. Gao, P. Badalov and L. Heumann, Org. Process Res. Dev., 2020, DOI: 10.1021/acs.oprd.0c00172; (d) F. Xue, X. Zhou, R. Zhou, X. Zhou, D. Xiao, W. Zhong, E. Gu, W. Guo, J. Xiang, K. Wang, L. Yang and Y. Qin, Org. Process Res. Dev., 2020, 24, 1772-1777.

3 (a) T. P. Sheahan, A. C. Sims, S. Zhou, R. L. Graham, A. J. Pruijssers, M. L. Agostini, S. R. Leist, A. Schafer, K. H. Dinnon III, L. J. Stevens, J. D. Chappel, X. Lu, T. M. Hughes, A. S. George, C. S. Hill, S. A. Montgomery, A. J. Brown, G. R. Bluemling, M. G. Natchus, M. Saindane, A. A. Kolykhalov, G. Painter, J. Harcourt, A. Tamin, N. J. Thornburg, R. Swanstrom, M. R. Denison and R. S. Baric, Sci. Transl. Med., 2020, 12, 1-15; (b) B. Halford, An emerging antiviral takes aim at COVID-19, Chem. Eng. News, 2020, 98, 22.

4 R. Cross, Merck \& Co. joins race for COVID-19 vaccines and therapies, Chem. Eng. News, 2020, 98, 12.

5 (a) G. R. Painter, G. R. Bluemling, M. G. Natchus and D. Guthrie, WO2019113462, 2018; (b) G. R. Painter, D. Perryman and G. R. Bluemling, WO2019173602, 2019.

6 Prices obtained through analysis of Indian import/export records.

7 (a) D. W. Verwoerd, H. Kohlhage and W. Zillig, Nature, 1961, 192, 1038-1040; (b) N. K. Kochetkov and E. I. Budovskii, Organic Chemistry of Nucleic Acids, Part B, Plenum Publishing Corporation, New York, 1972, pp. 269-348; (c) M. K. Purohit, E. Poduch, L. W. Wei, I. E. Crandall, T. To, K. C. Kain, E. F. Pai and L. P. Kotra, J. Med. Chem., 2012, 55, 9988; (d) G. R. Painter, D. B. Guthrie, G. R. Bluemling and M. G. Natchus, WO2016106050A1, 2016.

8 (a) M. A. Ivanov, E. V. Antonova, A. V. Maksimov, L. K. Pigusova, E. F. Belanov and L. A. Aleksandrova, Collect. Czech. Chem. Commun., 2006, 71, 1099; (b) R. F. Schinazi, F. Amblard, B. D. Cox, L. Bassit, L. Zhou and C. Gavegnano, WO2017165489, 2016.

9 (a) C. H. Wong, S. T. Chen, W. J. Hennen, J. A. Bibbs, Y. F. Wang, J. L. C. Liu, M. W. Pantoliano, M. Whitlow and P. N. Bryan, J. Am. Chem. Soc., 1990, 112, 945; (b) X.-F. Li, M.-H. Zong and R.-D. Yang, J. Mol. Catal. B: Enzym., 2006, 38, 48-53; (c) H. Wu, M. Zong and X. Chen, Biotechnol. Appl. Biochem., 2009, 53, 201; (d) R. Kumar, M. Kumar, J. Maity and A. K. Prasad, RSC Adv., 2016, 6, 82432.

10 F. Moris and V. Gotor, J. Org. Chem., 1993, 58, 653.

11 See ESI $\dagger$ for details. 